\title{
A novel cell factory for efficient production of ethanol from dairy waste
}

Jianming Liu', Shruti Harnal Dantoft ${ }^{1}$, Anders Würtz ${ }^{2}$, Peter Ruhdal Jensen ${ }^{1 *}$ and Christian Solem ${ }^{1 *}$

\begin{abstract}
Background: Sustainable and economically feasible ways to produce ethanol or other liquid fuels are becoming increasingly relevant due to the limited supply of fossil fuels and the environmental consequences associated with their consumption. Microbial production of fuel compounds has gained a lot of attention and focus has mostly been on developing bio-processes involving non-food plant biomass feedstocks. The high cost of the enzymes needed to degrade such feedstocks into its constituent sugars as well as problems due to various inhibitors generated in pretreatment are two challenges that have to be addressed if cost-effective processes are to be established. Various industries, especially within the food sector, often have waste streams rich in carbohydrates and/or other nutrients, and these could serve as alternative feedstocks for such bio-processes. The dairy industry is a good example, where large amounts of cheese whey or various processed forms thereof are generated. Because of their nutrient-rich nature, these substrates are particularly well suited as feedstocks for microbial production.

Results: We have generated a Lactococcus lactis strain which produces ethanol as its sole fermentation product from the lactose contained in residual whey permeate (RWP), by introducing lactose catabolism into a L. lactis strain CS4435 (MG1363 $\Delta^{3} / d h, \Delta p t a, \triangle a d h E, p C S 4268$ ), where the carbon flow has been directed toward ethanol instead of lactate. To achieve growth and ethanol production on RWP, we added corn steep liquor hydrolysate (CSLH) as the nitrogen source. The outcome was efficient ethanol production with a titer of $41 \mathrm{~g} / \mathrm{L}$ and a yield of $70 \%$ of the theoretical maximum using a fed-batch strategy. The combination of a low-cost medium from industrial waste streams and an efficient cell factory should make the developed process industrially interesting.

Conclusions: A process for the production of ethanol using L. lactis and a cheap renewable feedstock was developed. The results demonstrate that it is possible to achieve sustainable bioconversion of waste products from the dairy industry (RWP) and corn milling industry (CSLH) to ethanol and the process developed shows great potential for commercial realization.
\end{abstract}

Keywords: Lactococcus lactis, Lactose catabolism, Residual whey permeate, Corn steep liquor hydrolysate

\section{Background}

Currently, there is a growing demand for liquid fuels that can be produced in a sustainable manner from renewable raw materials. The potential that lies in using microorganisms for converting various feedstocks, e.g., plant biomass, into useful compounds including fuels, has already been recognized, and intense research is being carried out to establish robust and economically feasible

\footnotetext{
*Correspondence: perj@food.dtu.dk; chso@food.dtu.dk

${ }^{1}$ National Food Institute, Technical University of Denmark, 2800 Kongens

Lyngby, Denmark

Full list of author information is available at the end of the article
}

processes for production of biofuels [1]. Despite its lower energy density and higher hygroscopicity compared to longer chain alcohols (butanol or pentanol) [2], microbially produced ethanol presently dominates the biofuel market, and it is mainly produced from either refined sugar or starch-derived sugar [3, 4]. Although much focus has been on developing bio-processes, which are reliant on non-food plant biomass as feedstock, there are many challenges, including the high cost of enzymes needed for degrading the biomass, the recalcitrance of lignocellulose, a lack of microbial catalysts with sufficient robustness to withstand the inhibitors generated in pretreatment or that have a sufficiently broad spectrum 
of carbohydrate utilization [5-8]. As an alternative, one cheap abundant feedstock is cheese whey and its various processed forms, such as whey permeate or whey powder. Whey is a liquid byproduct of cheese production, obtained when draining the cheese curd. The worldwide production of cheese whey in 2012 was reported to be $4 \times 10^{7}$ tons and about $50 \%$ hereof was used for animal feed or otherwise disposed of as waste [9]. The latter is a serious problem as whey is discarded as liquid waste and has a high BOD (biochemical oxygen demand) and COD (chemical oxygen demand) [9].

The composition of whey varies according to the source of the milk and the technology used for its production. Normally, it contains approximately $90 \%$ water, $4 \%$ lactose, $1 \%$ protein, $0.7 \%$ minerals, and small amounts of vitamins [10]. Separation of whey proteins generates whey permeate and further extraction of lactose leads to permeate mother liquor (residual whey permeate, RWP), as a leftover product [11]. Fermentation of the main carbon source in whey (lactose) to ethanol has been studied for the last 30 years and most of the research has been focused on yeasts that naturally metabolize lactose, such as Kluyveromyces marxianus or Candida pseudotropicalis [10-13]. Metabolic engineering of Saccharomyces cerevisiae for lactose fermentation has also been reported [14]. There are, however, problems associated with these microorganisms, and these include a general low robustness, slow fermentation rate, and substrate-inhibition effects, which is why there is a need for better performing microbial candidates [10-14].

Lactococcus lactis, which is well known for its role in cheese production, has been demonstrated to have great potential as a cell factory, due to properties such as its high glycolytic flux, ability to metabolize a broad range of carbohydrates, well-characterized metabolic network, and ease of genetic manipulation [15]. Its long record of safe use is also an important asset, especially for the production of food ingredients [16]. Normally, most of the carbon flux in L. lactis is directed to lactate (homo-lactic fermentation). However, it can be successfully engineered to produce ethanol by knocking out alternative product pathways and introducing pyruvate decarboxylase and alcohol dehydrogenase heterologously [17]. A potential drawback of using $L$. lactis as a cell factory is its fastidious nature, i.e., its many nutritional growth requirements, which could perhaps make it less attractive for some industrial applications, e.g., for production of low-priced chemicals where, for competitive reasons, it is important to keep costs at a minimum. However, relatively cheap fermentation media have been developed, and additionally, the availability of nutrient-rich waste substrates may help circumvent problems associated with using L. lactis as a production host organism.
In the current work, we have engineered L. lactis to produce ethanol by fermenting lactose and we demonstrate ethanol production in a medium based on a waste stream, residual whey permeate, from the dairy industry containing partially hydrolyzed Corn Steep Liquor (CSLH) as a nitrogen source (Fig. 1). By using a fed-batch strategy, we achieve high-level ethanol production with a titer of $41 \mathrm{~g} / \mathrm{L}$ and a yield of $70 \%$ of the theoretical maximum, which corresponds to $5.2 \%$ $(w / v)$ of ethanol in the broth. We not only demonstrate how a large industrial waste stream can be used for production of a useful value-added chemical, but also how an existing environmental problem can be alleviated.

\section{Results and discussion}

\section{Redirection of $L$. lactis metabolism from homo-lactic to homo-ethanol}

L. lactis is normally a homo-lactic fermentative bacterium where about $90 \%$ of the glucose flux is directed to lactate (Table 1). As previously described [17], we successfully shifted the metabolic flux, of L. lactis, from lactate to ethanol by inactivating three lactate dehydrogenase (LDH) homologs -ldh, ldhB, ldhX (CS4099), the phosphotransacetylase (PTA, CS4234) and the native alcohol dehydrogenase (ADHE, CS4363) and introducing codon-optimized pyruvate decarboxylase (PDC)/ alcohol dehydrogenase (ADHB) sourced from Zymomonas mobilis, and finally obtained the ethanol-producing strain CS4435. As shown in Table 1, acetate and ethanol became the dominant products after the deletion of LDHs, and the production of acetate could then be eliminated by deleting PTA. CS4363 was unable to grow under anaerobic conditions because of the defect in cofactor regeneration ability. However, its growth could be restored in the presence of $\mathrm{O}_{2}$, where $\mathrm{NAD}^{+}$is recycled by NADH oxidase (NoxE) which results in acetoin as the main fermentation product. The introduction of PDC and ADHB restored complete cofactor recycling and bacterial growth under anaerobic conditions (Fig. 1), and the outcome was a homo-ethanol fermenting L. lactis (Table 1).

\section{The incorporation of lactose catabolism in the ethanol-producing strain}

CS4435 can produce ethanol as the sole fermentation product but cannot utilize lactose as a carbon source, since it is a derivative of the plasmid-free strain L. lactis MG1363 [18]. We therefore introduced the lactococcal plasmid-pLP712 (55.395 kbp), which encodes the entire lactose catabolism pathway [19], into strain CS4435 to make strain CS4435L, which could then grow on lactose. We then characterized the growth of CS4435L in 


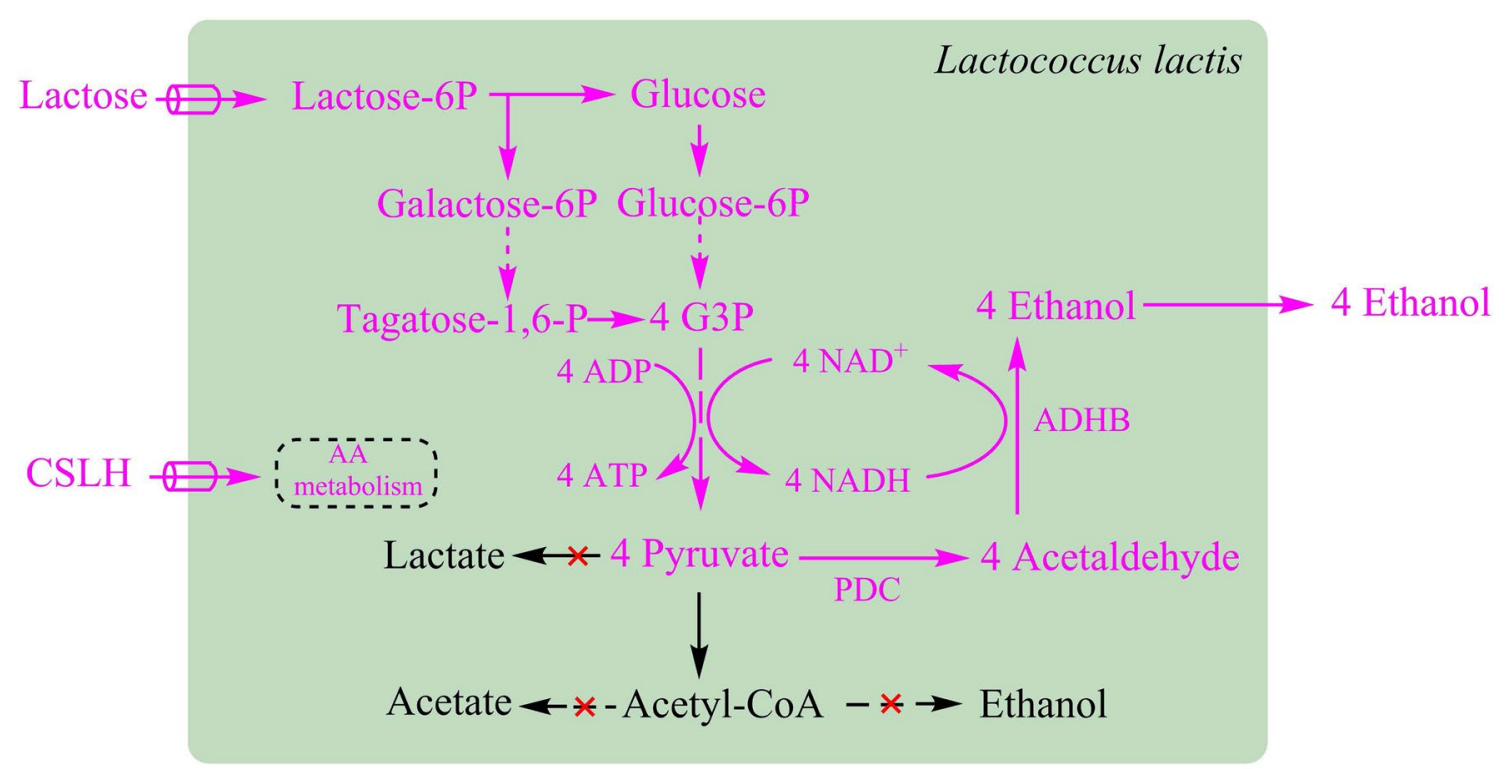

Fig. 1 Efficient cell factory for ethanol production. The incorporation of heterologous ethanol-producing pathway enables complete cofactor recycling. Competitive pathways have been inactivated (indicated with red mark). G3P glyceraldehyde 3-phosphate, PDC pyruvate decarboxylase from Zymomonas mobilis, ADHB ethanol dehydrogenase from Z. mobilis, AA amino acids, CSLH corn steep liquor hydrolysate

Table 1 Shifting the metabolism of $L$. lactis from homo-lactic to homo-ethanol

\begin{tabular}{|c|c|c|c|c|c|c|c|c|c|}
\hline Strains & Description & $\begin{array}{l}\text { Growth } \\
\text { conditions }\end{array}$ & $\begin{array}{l}\text { Carbon } \\
\text { balance (\%) }\end{array}$ & $\begin{array}{l}\text { Lactose } \\
\mathrm{mol} / \mathrm{mol}\end{array}$ & $\begin{array}{l}\text { Acetate } \\
\text { glucose }\end{array}$ & Formate & Acetoin & 2,3-Butanediol & Ethanol \\
\hline MG1363 & Wide type & Anaerobic & 90 & $1.8 \pm 0.1$ & ND & ND & ND & ND & ND \\
\hline CS4099 & $\begin{array}{l}\text { MG1363 } \Delta^{3} / d h, \\
(\Delta / d h, \triangle / d h B \text { and } \\
\Delta / d h X)\end{array}$ & Anaerobic & 85 & ND & $0.61 \pm 0.02$ & $1.58 \pm 0.07$ & $0.08 \pm 0.01$ & $0.09 \pm 0.01$ & $0.65 \pm 0.02$ \\
\hline CS4234 & MG1363 $\Delta^{3} / d h, \Delta p t a$ & Anaerobic & 88 & ND & ND & $0.82 \pm 0.05$ & $0.35 \pm 0.02$ & $0.16 \pm 0.03$ & $0.76 \pm 0.04$ \\
\hline CS4363 & $\begin{array}{l}\text { MG1363 } \Delta^{3} / d h, \Delta p t a, \\
\quad \triangle a d h E\end{array}$ & Aerobic & 85 & ND & ND & ND & $0.85 \pm 0.05$ & ND & ND \\
\hline CS4435 & $\begin{array}{c}\text { MG1363 } \Delta^{3} / d h, \Delta p t a \\
\triangle a d h E \text { pCS4268 }\end{array}$ & Anaerobic & 87 & ND & ND & ND & ND & ND & $1.75 \pm 0.06$ \\
\hline
\end{tabular}

Strains were cultivated in defined SA medium with glucose and samples were collected after $24 \mathrm{~h} . \mathrm{CO}_{2}$ is included for calculating the carbon balance. Values are averages of three independent experiments and standard deviations are indicated

Idh $(I d h B, I d h X)$ lactate dehydrogenase, pta phosphotransacetylase, adhE alcohol dehydrogenase, pCS4268 pTD6-pdc-adhB (pdc, pyruvate decarboxylase from Zymomonas mobilis, adhB ethanol dehydrogenase from Z. mobilis)

defined synthetic amino acid (SA) medium [20] with $7.2 \mathrm{~g} / \mathrm{L}$ lactose as the sole carbon source. As shown in Fig. 2, all the lactose were completely consumed within $11 \mathrm{~h}$ and the only fermentation product was ethanol. An ethanol concentration of $3.2 \mathrm{~g} / \mathrm{L}$ was obtained with the yield of $0.45 \mathrm{~g}$ ethanol/g lactose, corresponding to $83 \%$ of the theoretical maximum, with a growth rate close to $0.6 \mathrm{~h}^{-1}$. It was possible to increase the ethanol titer to 6.7, 10.3 , and $12.0 \mathrm{~g} / \mathrm{L}$, when the initial lactose concentration was increased to $15.1,24.0$, and $31.8 \mathrm{~g} / \mathrm{L}$, respectively (Table 2).
The results obtained clearly demonstrate the potential of $L$. lactis as a cell factory for converting lactose into value-added compounds. Dairy isolates of $L$. lactis are all able to metabolize lactose efficiently as they contain plasmids expressing the necessary genes. However, in our case, we started from a non-lactose-metabolizing laboratory strain, MG1363, which is a plasmid-free derivative of the dairy isolate NCDO712. MG1363 is easy to engineer, grows well, and has been well characterized, and this is the main reason for why it was chosen for the current study. The lactose plasmid which we introduced 


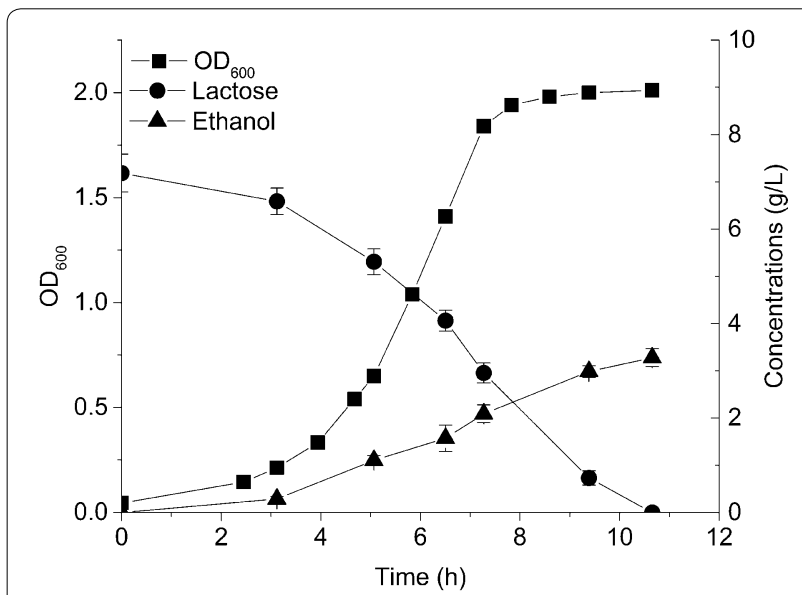

Fig. 2 Characterization of CS4435L in defined medium containing lactose. CS4435L was grown in defined SA medium with $7.2 \mathrm{~g} / \mathrm{L}$ lactose as the only energy source. Cell density (filled squares), lactose concentration (filled circles), and ethanol concentration (filled triangles) are displayed. Experiments were conducted in duplicate and error bars indicate standard deviations into the ethanol forming strain, pLP712, originated from NCDO712, which contains four other plasmids that potentially could interfere with genetic engineering. CS4435L is able to take up lactose via a lactose specific phosphotransferase system (PTS), encoded by lacEF, then phosphorylated lactose is hydrolyzed to glucose and galactose-6-phosphate (gal-6-P) by the phospho$\beta$-galactosidase (lacG). The glucose moiety enters into glycolysis, while gal-6-P is degraded via the tagatose-6-P pathway $(\operatorname{lac} A B C D)$. All the genes involved are located on the pLP712 plasmid (Fig. 3). Another way of metabolizing lactose has been reported, where lactose is transported by a lactose permease and cleaved intracellularly to glucose and galactose [21]. The galactose moiety is subsequently metabolized by the Leloir pathway. Since, in this case, lactose is taken up by a permease that depends on ATP hydrolysis, it is less efficient in terms of energy expenditure. For this reason, and because of its proven efficiency, we chose to use the PTS-based system. The growth rate obtained for CS4435L in lactose-SA medium was $0.6 \mathrm{~h}^{-1}$, which was only slightly below that obtained when growing on glucose $\left(0.7 \mathrm{~h}^{-1}\right)$ [20], which furthermore proved that the strategy chosen was the correct one.

\section{Development and optimization of a low-cost medium}

As mentioned above, CS4435L was able to grow well in a defined medium containing lactose as the sole energy source. In order to create a sustainable and economical bioprocess for ethanol production, we attempted to use a waste stream-residual whey permeate (RWP) as feedstock. As mentioned, RWP is the permeate mother liquor after extracting lactose from whey permeate. It was obtained from Arla Foods Ingredients Group P/S (http:// www.arlafoodsingredients.com/) and its composition can be seen in Table 3. Relatively low amounts of amino acids were found to be present in RWP, and no cell growth or ethanol formation was observed in medium solely consisting of RWP (for all experiments three times diluted RWP containing $50 \mathrm{~g} / \mathrm{L}$ lactose was used) (Fig. 4a, b). This was not surprising considering the amino acid requirements previously reported for L. lactis [20]. Therefore, different kinds of nitrogen sources at various concentrations were tested in order to optimize growth of the ethanol strain. Figure 4 shows that CS4435L was unable to grow in whey medium supplemented with inorganic $\mathrm{NH}_{4} \mathrm{Cl}$, but the addition of yeast extract (YE) resulted in good growth. In RWP medium with $0.5 \%(w / v)$ YE,

Table 2 Optimization of lactose concentrations in different types of media

\begin{tabular}{|c|c|c|c|c|c|}
\hline Lactose (g/L) & Media types & $O D_{600}$ & Ethanol (g/L) & Yield (g ethanol/g lactose) & Conversion efficiency $^{a}$ \\
\hline 7.2 & $S A^{b}$ & 2.0 & 3.2 & 0.45 & 0.83 \\
\hline 15.1 & $S A^{b}$ & 2.3 & 6.7 & 0.44 & 0.82 \\
\hline 24.0 & $S A^{b}$ & 2.9 & 10.3 & 0.43 & 0.80 \\
\hline 31.8 & $S A^{b}$ & 3.6 & 12.0 & 0.38 & 0.71 \\
\hline 32.0 & $R W P+Y E^{C}$ & 7.2 & 13.4 & 0.42 & 0.78 \\
\hline 40.0 & $\mathrm{RWP}+\mathrm{CSLH}^{\mathrm{d}}$ & 4.0 & 17.5 & 0.44 & 0.82 \\
\hline 80.0 & $\mathrm{RWP}+\mathrm{CSLH}^{\mathrm{e}}$ & 6.0 & 30.6 & 0.40 & 0.71 \\
\hline $80.0^{9}$ & $\mathrm{RWP}+\mathrm{CSLH}^{\mathrm{f}}$ & 6.0 & 41.0 & 0.38 & 0.70 \\
\hline
\end{tabular}

a Conversion efficiency was calculated based on the theoretical maximal yield ( 0.538 ethanol $/ \mathrm{g}$ lactose)

b The composition of SA medium can be seen in reference 20. It includes 19 amino acids, vitamins, and salts. Glucose was replaced by lactose

c Diluted RWP (residual whey permeate) and $0.5 \%(w / v)$ YE (yeast extract)

d-f Diluted RWP (residual whey permeate) and $2.5 \%(w / v)$ CSLH (corn steep liquor hydrolysate), prepared by condition $\mathrm{H} 1$

${ }^{9}$ Fed-batch was performed with initial $80 \mathrm{~g} / \mathrm{L}$ lactose and the details can be found in Fig. 7 


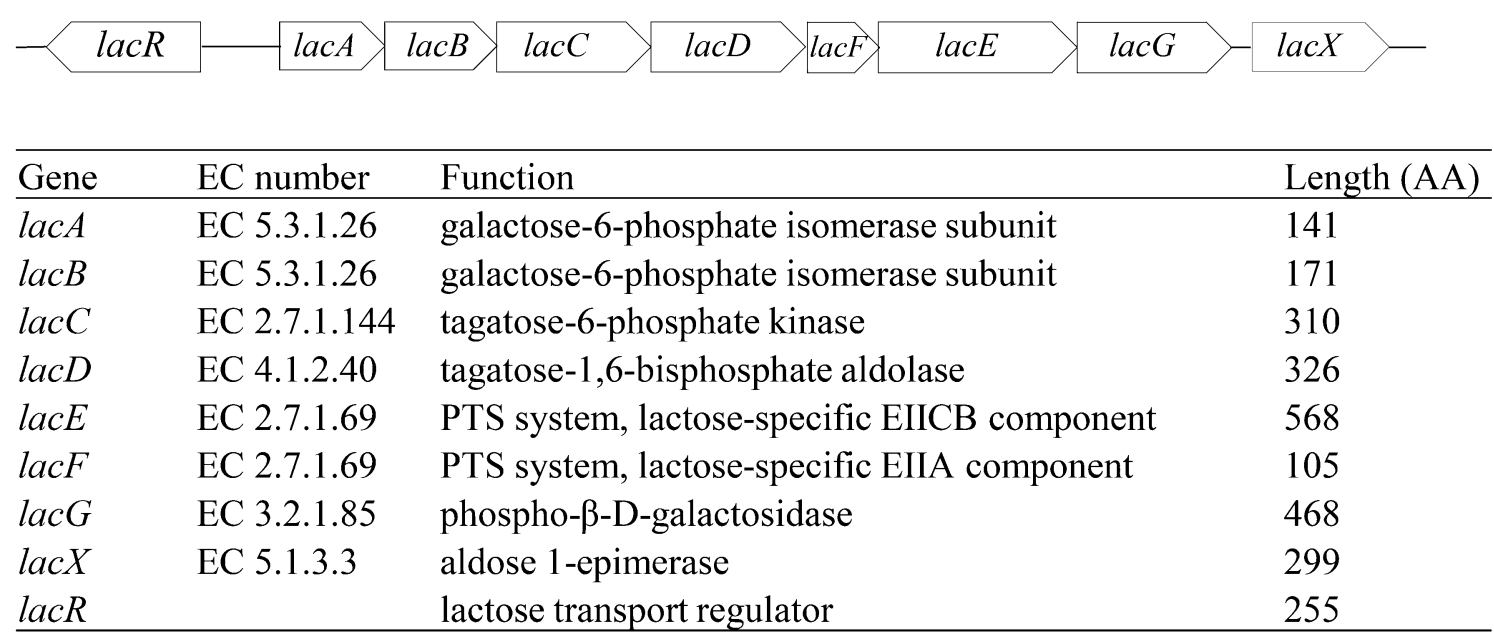

Fig. 3 The lactose catabolism pathway. The location of each gene is displayed above and its EC number, specific function and amino acid (AA) length are summarized below

Table 3 The composition of residual whey permeate ${ }^{a}$

\begin{tabular}{ll}
\hline Composition & Concentration \\
\hline Lactose & $150 \mathrm{~g} / \mathrm{L}$ \\
Galactose & $3 \mathrm{~g} / \mathrm{L}$ \\
Aspartate & $0.252 \mathrm{mM}(\mathrm{mmol} / \mathrm{L})$ \\
Threonine & $0.076 \mathrm{mM}$ \\
Serine & $0.088 \mathrm{mM}$ \\
Glutamate & $1.464 \mathrm{mM}$ \\
Proline & $0.384 \mathrm{mM}$ \\
Glycine & $0.904 \mathrm{mM}$ \\
Alanine & $0.24 \mathrm{mM}$ \\
Cysteine & $0.096 \mathrm{mM}$ \\
Valine & $0.072 \mathrm{mM}$ \\
Methionine & $0.124 \mathrm{mM}$ \\
isoleucine & $0.04 \mathrm{mM}$ \\
Leucine & $0.092 \mathrm{mM}$ \\
Histidine & $0.208 \mathrm{mM}$ \\
Lysine & $0.304 \mathrm{mM}$ \\
Arginine & $0.096 \mathrm{mM}$
\end{tabular}

${ }^{a}$ Residual whey permeate is a concentrate of the residue remaining after lactose extraction from whey permeate

a final cell density $\left(\mathrm{OD}_{600}\right)$ of 6.5 was achieved after $12 \mathrm{~h}$ of fermentation, and the final ethanol concentration was nearly $19 \mathrm{~g} / \mathrm{L}$. According to previous studies, YE is the best choice, among various complex nitrogen sources, for supporting growth of lactic acid bacteria [22]. However, due to its high price (currently $7000 \sim 10,000 \$ /$ ton), it is not cost-effective to include it in a process for producing ethanol. In an economic analysis of microbial production of lactic acid, YE was estimated to contribute to over
$30 \%$ of the total production costs [23], which makes it necessary to find cheaper alternatives. Corn steep liquor (CSL), which is a byproduct of the corn milling industry, is a cheaper nitrogen source that currently costs around $500 \$ /$ ton. We tested CSL as a potential replacement for YE. At all concentrations [from 0.1 to $2.5 \%$ (w/v)], however, the final biomass concentration was quite low with almost no ethanol produced. By combining $0.1 \%(\mathrm{w} / \mathrm{v})$ YE with CSL, a stimulation of growth was observed, but it was quite small (Fig. 4a, b). CSL did not support cell growth well and we speculated that it could be due to a low concentration of free and available amino acid concentration, as they could be locked up in insoluble proteins. To test this, we therefore attempted to hydrolyze CSL with different concentrations of $\mathrm{H}_{2} \mathrm{SO}_{4}$. These treatments involved very small amounts of sulfuric acid (0.05-0.5\% concentrated $\mathrm{H}_{2} \mathrm{SO}_{4}$ added to CSL with 20-30\% solid content). The $\mathrm{H} 1$ hydrolysate (CSL treated with $0.05 \% \mathrm{H}_{2} \mathrm{SO}_{4}$ ) provided the best results. When $2.5 \%(\mathrm{w} / \mathrm{v})$ corn steep liquor hydrolysate (CSLH) concentration was used, a high cell density of $4.5\left(\mathrm{OD}_{600}\right)$ and a high ethanol titer $(17.5 \mathrm{~g} / \mathrm{L})$ were obtained after $30 \mathrm{~h}$ of fermentation from $50 \mathrm{~g} / \mathrm{L}$ lactose. A direct correlation between CSLH added and cell biomass, and ethanol production was observed (Fig. 4c, d). Increasing the amount of sulfuric acid in the pretreatment $\left(\mathrm{H} 2,0.25 \% \mathrm{H}_{2} \mathrm{SO}_{4}\right)$ did not improve cell growth and ethanol production, and even had a negative effect at the highest concentration tested $\left(\mathrm{H} 3,0.5 \% \mathrm{H}_{2} \mathrm{SO}_{4}\right)$. In the latter case, the cell density obtained was only $3.0\left(\mathrm{OD}_{600}\right)$ and the final ethanol titer was $11 \mathrm{~g} / \mathrm{L}$ when using $2.5 \%$ (w/v) CSLH.

CSLH proved to be a good source of nitrogen for L. lactis growth and efficient ethanol production, although the 


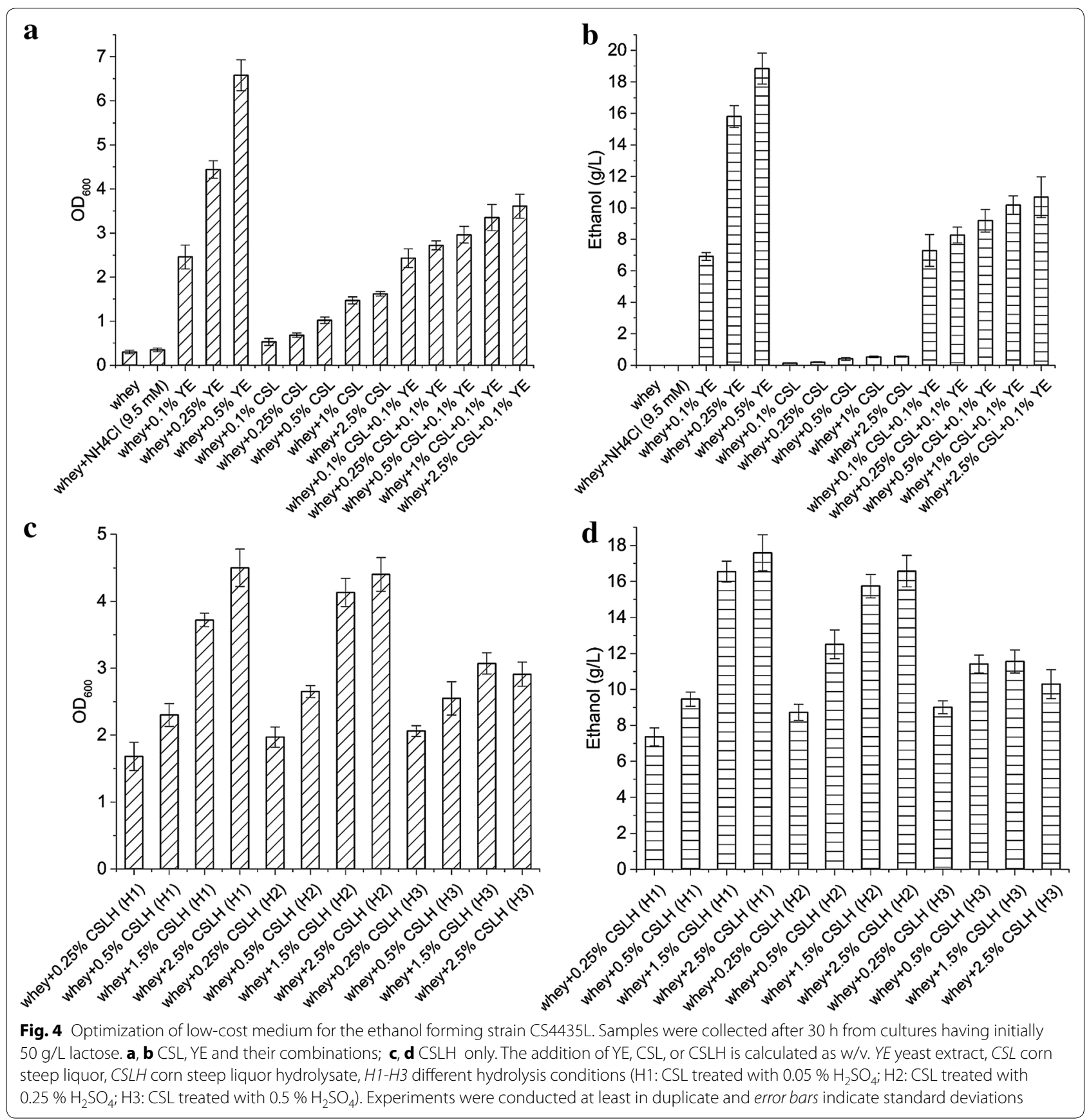

highest cell density obtained $\left[4.5\left(\mathrm{OD}_{600}\right)\right.$ at $2.5 \%(\mathrm{w} / \mathrm{v})$ CSLH (H1)] was below that obtained in the presence of $0.5 \%(\mathrm{w} / \mathrm{v})$ YE (6.5). However, this should be considered as beneficial as biomass formation is often at the cost of ethanol yield. In our case, for L. lactis, the acid-digested CSL supported cell growth much better than untreated CSL, which may demonstrate that the protein present in CSL is unavailable for growth. Despite the fact that our strain possesses a cell-envelope bound protease encoded by genes present on plasmid pLP712, these proteins were apparently inaccessible, most likely because of their insoluble nature. This cell-envelope bound protease enables growth of L. lactis dairy isolates in milk, which is low in free amino acids and peptides [19]. In our case, the low level hydrolysis probably resulted in the formation of peptides and peptides are a preferred source of amino acids for this particular organism which possesses an impressive repertoire of intracellular peptidases 
as well as various uptake systems for peptides [24]. The negative effect of excessive hydrolysis (H3) may have caused a decrease in the amount of available peptides or perhaps could have resulted in formation of inhibitory compounds during acid hydrolysis $[25,26]$. It is thus not likely that this simple pretreatment method would be beneficial for other microorganisms that are not adapted to growth in rich environments. Our work demonstrates that a fastidious microorganism should not be ruled out as a potential and perhaps superior industrial workhorse for the production of special chemicals [27].

\section{Ethanol production in the low-cost medium}

For optimizing the growth medium, final cell density and ethanol titer were determined. To characterize growth as well as ethanol formation in more detail, fermentations were closely monitored. Medium containing YE was included for comparison. In Fig. 5b, it can be seen that $40 \mathrm{~g} / \mathrm{L}$ lactose was completely consumed within $31 \mathrm{~h}$ and that the final cell density $\left(\mathrm{OD}_{600}\right)$ reached 4.0 after $14.5 \mathrm{~h}$ in medium with $2.5 \%(\mathrm{w} / \mathrm{v})$ CSLH (H1). The ethanol concentration increased linearly to $17.5 \mathrm{~g} / \mathrm{L}$ with $82 \%$ of the theoretical maximum. However, in the presence of $0.5 \%(\mathrm{w} / \mathrm{v})$ YE, the ethanol yield was slightly less (78 \% of the theoretical maximum), although growth was faster and the final cell biomass was higher $\left(\mathrm{OD}_{600}=7.2\right.$, Fig. $\left.5 \mathrm{a}\right)$. This can perhaps be explained in light of the fact that YE stimulates bacterial growth well and therefore more of the carbon flux is directed to cell biomass, leading to more biomass and less of the desired product. This is not ideal for production of chemicals and several studies have focused on reducing excess biomass formation to direct more of the carbon flux toward target chemicals. Becker et al. engineered Corynebacterium glutamicum to lower the biomass yield and finally got more lysine [28]. Hui Wu et al. obtained improved lactate concentration with lower biomass amounts [29]. In the present study, the replacement of YE with cheap CSLH resulted in a $44 \%$ decrease in cell biomass yield but an overall increase in ethanol production yield (about $5 \%$ ).

The volumetric productivity of ethanol in the YE containing medium $(0.96 \mathrm{~g} / \mathrm{L} / \mathrm{h})$ was higher than that containing CSLH $(0.56 \mathrm{~g} / \mathrm{L} / \mathrm{h})$ (Fig. 5). We believe that the productivity in the CSLH medium can be improved through further medium optimization. It has been reported that the ethanol fermentation ability of $K$. fragilis was improved significantly when deproteinized whey (containing $0.5 \%$ peptone) was supplemented with ergosterol and linoleic acid [30]. Adding ammonium sulfate or dipotassium hydrogen phosphate has also been demonstrated to lead to an improvement [31]. There is also the option of using adaptive evolution to improve performance in RWP-based media. On the other hand, the possibility to use YE for industrial ethanol fermentation cannot be excluded if the cost of YE becomes economically competitive. Finally, the option of combining YE with CSLH has not yet been tested, and could potentially improve both yield and productivity.
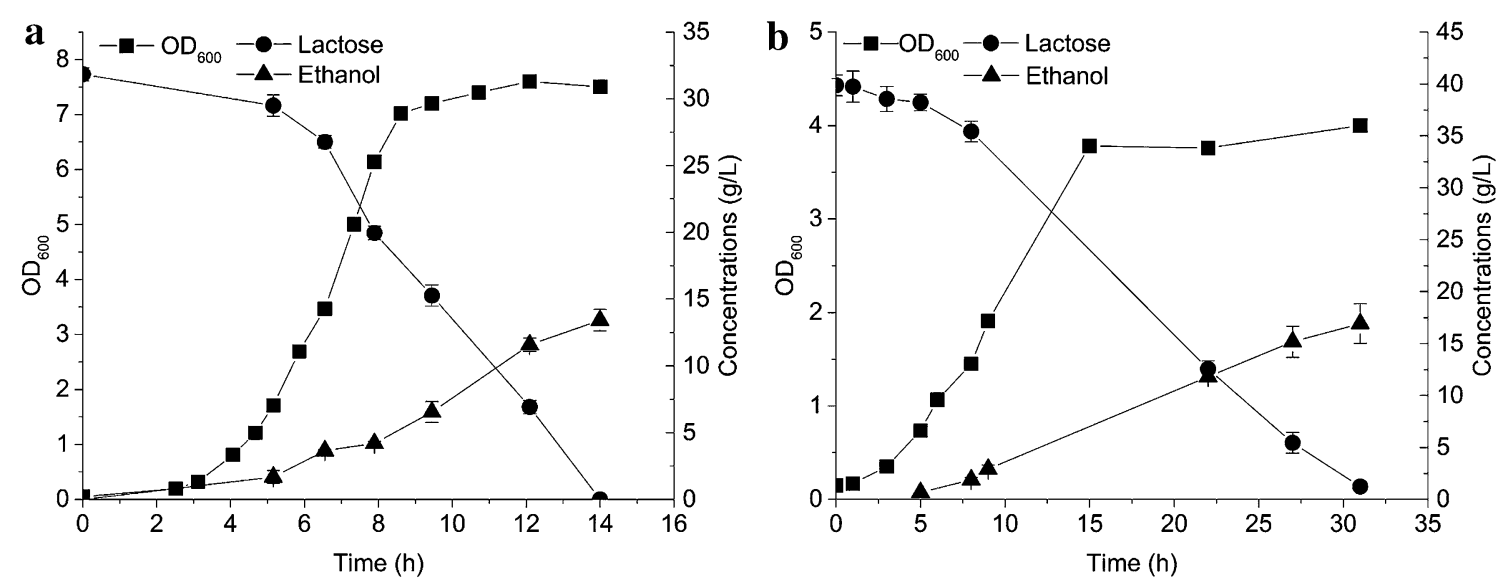

Fig. 5 Comparing growth and ethanol formation of CS4435L in residual whey permeate medium with two different nitrogen sources. The medium only contains diluted residual whey permeate (RWP) without the addition of any vitamin or salt, except yeast extract (YE) or corn steep liquor hydrolysate (CSLH) as nitrogen sources. a The fermentation was carried out in diluted RWP medium containing initially $32 \mathrm{~g} / \mathrm{L}$ lactose and $0.5 \%$ $(\mathrm{w} / \mathrm{v})$ yeast extract; b The fermentation was carried out in diluted RWP medium containing initially $40 \mathrm{~g} / \mathrm{L}$ lactose and $2.5 \%$ (w/v) CSLH. CSLH was prepared based on $\mathrm{H} 1$ condition ( $\mathrm{CSL}$ treated with $0.05 \% \mathrm{H}_{2} \mathrm{SO}_{4}$ ). Cell density (filled squares), lactose concentration (filled circles), and ethanol concentration (filled triangles) are displayed. Experiments were conducted in duplicate and error bars indicate standard deviations 


\section{Fed-batch fermentation}

Increasing ethanol titer in the fermentation broth is crucially important in order to reduce distillation costs in down-stream processing. It has been previously reported that at least $4 \%(\mathrm{w} / \mathrm{w})$ of ethanol should be present in the fermentation broth to lower the cost associated with distillation [32, 33]. We carried out fermentation experiments with an initial concentration of $80 \mathrm{~g} / \mathrm{L}$ lactose, and the lactose was totally consumed in $55 \mathrm{~h}$ where the ethanol titer reached $30.6 \mathrm{~g} / \mathrm{L}$ (yield of $71 \%$ ) (Fig. 6). We found that having more than $80 \mathrm{~g} / \mathrm{L}$ lactose present from the beginning of the fermentation experiment was not beneficial in terms of ethanol titer, which may be due to a high osmotic pressure or decreased cell viability in the presence of higher ethanol concentrations [34, 35]. Because of this, a fed-batch fermentation strategy was devised and a final titer of $41 \mathrm{~g} / \mathrm{L}$ ethanol was obtained after nearly $90 \mathrm{~h}$ with the yield of $70 \%$ (Fig. 7). It was obvious that the ethanol formation rate was significantly lower in the last $40 \mathrm{~h}$, demonstrating the weaker cell viability or lower enzyme activities as the fermentation time was extended [36].

These results are very encouraging and we believe that the titers and yields still can be improved. Koebmann et al. previously have demonstrated that the glycolytic flux in non-growing L. lactis can be increased after the introduction of F1-ATPase and similarly Hadicke et al. observed the lactate production rate increased in

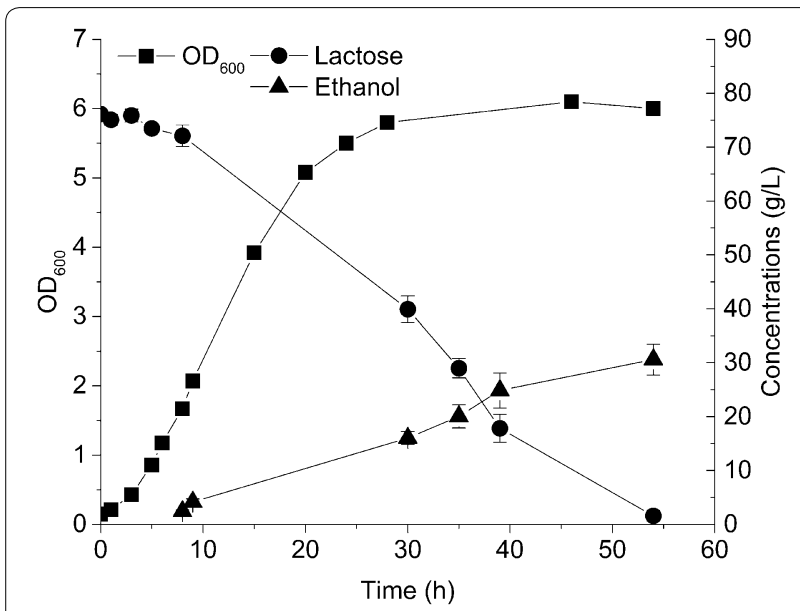

Fig. 6 Time-course fermentation. Characterization of growth and ethanol production/lactose consumption in whey-based medium containing corn steep liquor hydrolysate (CSLH). The fermentation was performed with CS4435 $\mathrm{L}$ in diluted residual whey permeate medium containing initially $80 \mathrm{~g} / \mathrm{L}$ lactose and $2.5 \%$ (w/v) CSLH CSLH was prepared based on $\mathrm{H} 1$ condition (CSL treated with $0.05 \%$ $\mathrm{H}_{2} \mathrm{SO}_{4}$ ). Cell density (filled squares), lactose concentration (filled circles), and ethanol concentration (filled triangles) are displayed. Experiments were conducted in duplicate and error bars indicate standard deviations

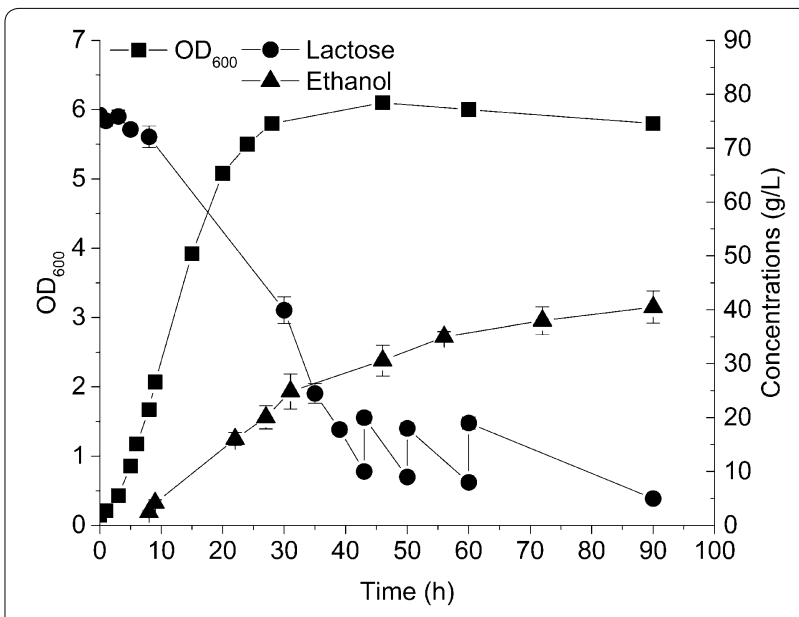

Fig. 7 Fed-batch culturing of ethanol forming strain CS4435L for high-titer ethanol production. Fed-batch was performed with initial $80 \mathrm{~g} / \mathrm{L}$ lactose and $2.5 \%$ (w/v) CSLH in the residual whey permeate medium and $500 \mathrm{~g} / \mathrm{L}$ lactose stock solution was used for feeding. CSLH was prepared based on $\mathrm{H} 1$ condition (CSL treated with $0.05 \%$ $\mathrm{H}_{2} \mathrm{SO}_{4}$ ). Cell density (filled squares), lactose concentration (filled circles), and ethanol concentration (filled triangles) are displayed. Experiments were conducted in duplicate and error bars indicate standard deviations

Escherichia coli when ATP consumption cycle incorporated $[36,37]$. Both studies thus indicate that the ethanol flux can be further improved through energy manipulation inside the cells. Summing up, we have developed a robust strain that efficiently can convert a dairy waste product into a value-added product (ethanol) and we have demonstrated the potential of using the L. lactis chassis as a cell factory.

\section{Conclusion}

We provide a good example of how L. lactis can serve as a cell factory, by engineering a derivative of $L$. lactis that can convert waste stream materials from the dairy industry into ethanol. The engineering efforts include substantial rewiring of metabolism, where we incorporate lactose metabolism into an ethanol producer (including the inactivation of LDH, PTA, ADHE, and introduction of heterologous PDC and ADHB). Finally, we achieve a high titer of $41 \mathrm{~g} / \mathrm{L}$ ethanol with the yield of $70 \%$ of the theoretical maximum by using a low-cost medium that contains a cheap nitrogen source (corn steep liquor hydrolysate) in combination with a fed-batch strategy. We believe that we may develop a cost-effective bioconversion process that can turn waste products from the dairy industry (RWP) and the corn milling industry (CSLH) into value-added ethanol which has immediate potential for commercialization. 


\section{Methods}

\section{Strains and plasmids}

The plasmid-free strain Lactococcus lactis subsp. cremoris MG1363 or derivatives were used for the studies described in this article [18]. Escherichia coli strain ABLE-C (E. coli C lac $\left(\mathrm{LacZ}^{-}\right)\left[\mathrm{Kan}^{\mathrm{r}} \mathrm{McrA}^{-} \mathrm{McrCB}^{-}\right.$ $\left.\mathrm{McrF}^{-} \mathrm{Mrr}^{-} \operatorname{HsdR}\left(\mathrm{r}_{\mathrm{k}}^{-} \mathrm{m}_{\mathrm{k}}^{-}\right)\right]\left[\mathrm{F}^{\prime}\right.$ proAB $\operatorname{lacI}^{\mathrm{q}} \mathrm{Z} \Delta \mathrm{M} 15$ $\operatorname{Tn} 10\left(\operatorname{Tet}^{\mathrm{r}}\right)$ ] (Stratagene) was used for cloning purposes. The lactose metabolism plasmid pLP712 (55,395 bp) was extracted from the dairy isolate NCDO712 based on the method of Andersen [38].

\section{Growth condition}

E. coli strains were grown aerobically at $30{ }^{\circ} \mathrm{C}$ in LuriaBertani broth [39]. For growth experiments, L. lactis was grown in $100 \mathrm{ml}$ flasks without shaking in defined SA medium [20], where glucose was replaced by lactose, or residual whey permeate medium (RWP). RWP, which was provided from Arla Foods Ingredients Group P/S (http://www.arlafoodsingredients.com/), is the mother liquor from lactose production and its composition is shown in Table 3. When required, yeast extract (SigmaAldrich, USA) was used as a nitrogen source. Antibiotics were added in the following concentrations: erythromycin: $200 \mu \mathrm{g} / \mathrm{ml}$ for $E$. coli and $5 \mu \mathrm{g} / \mathrm{ml}$ for L. lactis, tetracycline: $8 \mu \mathrm{g} / \mathrm{ml}$ for $E$. coli and $5 \mu \mathrm{g} / \mathrm{ml}$ for $L$. lactis, chloramphenicol: $20 \mu \mathrm{g} / \mathrm{ml}$ for $E$. coli and $5 \mu \mathrm{g} / \mathrm{ml}$ for $L$. lactis.

\section{DNA techniques}

All manipulations were performed according to Sambrook et al [39]. PfuX7 polymerase was used for PCR applications [40]. Chromosomal DNA from L. lactis was isolated using the method described for $E$. coli with the modification that cells were treated with $20 \mu \mathrm{g}$ of lysozyme per $\mathrm{ml}$ for $2 \mathrm{~h}$. Cells of $E$. coli were transformed using electroporation. L. lactis was made electro competent as described previously by Holo and Nes with the following modifications [41]: the cells were grown with $1 \%$ glycine, and at an optical density of $0.5(600 \mathrm{~nm})$ ampicillin was added to a final concentration of $20 \mu \mathrm{g} \mathrm{ml}^{-1}$ and incubation was continued at $30^{\circ} \mathrm{C}$ for $30 \mathrm{~min}$.

\section{Analytical methods}

Cell growth was regularly measured by $\mathrm{OD}_{600}$, and the quantification of lactose, glucose, lactate, formate, acetate, ethanol, acetoin and 2,3-butanediol was carried out using an Ultimate 3000 high-pressure liquid chromatography system (Dionex, Sunnyvale, USA) equipped with a Aminex HPX-87H column (Bio-Rad, Hercules, USA) and a Shodex RI-101 detector (Showa Denko K.K., Tokyo, Japan). For the detection of pyruvate, the DAD-3000 diode array detector (Dionex, Sunnyvale, USA) was used.
The column oven temperature was set at $60{ }^{\circ} \mathrm{C}$ and the mobile phase consisted of $5 \mathrm{mM} \mathrm{H}_{2} \mathrm{SO}_{4}$, at a flow rate of $0.5 \mathrm{ml} / \mathrm{min}$. As for the detection of amino acids in residual whey permeate, the filtered sample was first hydrolyzed with $6 \mathrm{M} \mathrm{HCl}$ and then separated by ion exchange chromatography and detected after oxidation and derivatization with $o$-phthaldialdehyde [42].

\section{Corn steep liquor hydrolysis}

Corn steep liquor (CSL) was purchased from SigmaAldrich (St. Louis, MO) with 40-60 \% solid content. Different hydrolysis conditions were applied to make corn steep liquor hydrolysate (CSLH). H1 condition: original CSL was diluted two times with water, and then $50 \mu \mathrm{l}$ concentrated sulfuric acid was mixed with $100 \mathrm{ml}$ diluted CSL. The mixture was kept at $121^{\circ} \mathrm{C}$ for $15 \mathrm{~min}$ and subsequently $\mathrm{pH}$ was adjusted to 6.8-7.1 with the addition of $10 \mathrm{M} \mathrm{NaOH}$ solution. $\mathrm{H} 2$ condition: original CSL was diluted two times with water and then $250 \mu \mathrm{l}$ concentrated sulfuric acid was mixed with $100 \mathrm{ml}$ diluted CSL. The mixture was kept at $121{ }^{\circ} \mathrm{C}$ for $15 \mathrm{~min}$ and subsequently $\mathrm{pH}$ was adjusted to $6.8-7.1$ with the addition of $10 \mathrm{M} \mathrm{NaOH}$ solution. $\mathrm{H} 3$ condition: original CSL was diluted two times with water and then $500 \mu \mathrm{l}$ concentrated sulfuric acid was mixed with $100 \mathrm{ml}$ diluted CSL. The mixture was kept at $121{ }^{\circ} \mathrm{C}$ for $15 \mathrm{~min}$ and subsequently $\mathrm{pH}$ was adjusted to 6.8-7.1 with the addition of $10 \mathrm{M} \mathrm{NaOH}$ solution.

\section{Ethanol fermentation}

Defined SA medium was used for screening of lactosemetabolizing strain with lactose as the only carbon source. For nitrogen source optimization, $50 \mathrm{~g} / \mathrm{L}$ lactose (diluted RWP) was mixed with different concentrations of nitrogen sources $\left(\mathrm{NH}_{4} \mathrm{Cl}\right.$, yeast extract, CSL or CSLH) in $25 \mathrm{ml}$ tube with a volume of $10 \mathrm{ml}$. For ethanol production, RWP was diluted and used as the main substrate for fermentation without the addition of any vitamins or salts, except $2.5 \%(\mathrm{w} / \mathrm{v})$ CSLH. CS4435L was grown in a $125 \mathrm{ml}$ flask with $100 \mathrm{ml}$ of medium with slow magnetic stirring and no aeration. The cultivation was carried out at $30{ }^{\circ} \mathrm{C}$. Fed-batch was performed with initial $80 \mathrm{~g} / \mathrm{L}$ lactose and $2.5 \%(\mathrm{w} / \mathrm{v}) \mathrm{CSLH}$, and $500 \mathrm{~g} / \mathrm{L}$ lactose stock solution was used for feeding. The feeding was performed when the lactose concentration was lower than $10 \mathrm{~g} / \mathrm{L}$ and after rapid injection it returned to around $20 \mathrm{~g} / \mathrm{L}$. Samples were collected periodically for determining cell density, lactose, and ethanol concentrations.

\section{Abbreviations}

L. lactis: Lactococcus lactis; RWP: residual whey permeate; CSLH: corn steep liquor hydrolysate; YE: yeast extract; $/ d h$ : genes encoding for lactate dehydrogenase; pta: gene encoding for phosphotransacetylase; adhE: gene encoding 
for the native alcohol dehydrogenase; PDC: pyruvate decarboxylase from Zymomonas mobilis; ADHB: ethanol dehydrogenase from Z. mobilis. AA, amino acids; $\mathrm{NADH}$ or $\mathrm{NAD}^{+}$: reduced or oxidized form of nicotinamide adenine dinucleotide; $\mathrm{OD}_{600}$ : optical density at wavelength of $600 \mathrm{~nm}$; SA: synthetic amino acid medium

\section{Authors' contributions}

JML and CS carried out all the experimental work and analyzed the data and wrote the manuscript. CS and PRJ participated in the design of the study and wrote the manuscript. SHD provided useful suggestions for experiment design and revised the manuscript critically. AW provided residual whey permeate for the study and revised the manuscript. All authors read and approved the final manuscript.

\section{Author details}

${ }^{1}$ National Food Institute, Technical University of Denmark, 2800 Kongens Lyngby, Denmark. ${ }^{2}$ Arla Foods Ingredients Group P/S, Sønderhøj 10-12, 8260 Viby J, Denmark.

\section{Acknowledgements}

This work was supported by a grant from the Innovation fund Denmark (4106-00037B)

\section{Competing interests}

The authors declare that they have no competing interests.

Received: 16 November 2015 Accepted: 21 January 2016

Published online: 26 February 2016

\section{References}

1. Wyman CE. BIOMASS ETHANOL: technical Progress, Opportunities, and Commercial Challenges. Annu Rev Energy Environ. 1999;24:189-226.

2. Huang $H$, Singh V, Qureshi N. Butanol production from food waste: a novel process for producing sustainable energy and reducing environmental pollution. Biotechnol Biofuels. 2015:8:147.

3. Joelsson E, Erdei B, Galbe M, Wallberg O. Techno-economic evaluation of integrated first- and second-generation ethanol production from grain and straw. Biotechnol Biofuels. 2016;9:1.

4. Erdei B, Barta Z, Sipos B, Réczey K, Galbe M, Zacchi G. Ethanol production from mixtures of wheat straw and wheat meal. Biotechnol Biofuels. 2010;3:16.

5. Mielenz JR. Ethanol production from biomass: technology and commercialization status. Curr Opin Microbiol. 2001;4:324-9.

6. Pu Y, Hu F, Huang F, Davison BH, Ragauskas AJ. Assessing the molecular structure basis for biomass recalcitrance during dilute acid and hydrothermal pretreatments. Biotechnol Biofuels. 2013;6:15.

7. Wi SG, Cho EJ, Lee D-S, Lee SJ, Lee YJ, Bae H-J. Lignocellulose conversion for biofuel: a new pretreatment greatly improves downstream biocatalytic hydrolysis of various lignocellulosic materials. Biotechnol Biofuels. 2015;8:228.

8. Vermaas JV, Petridis L, Qi X, Schulz R, Lindner B, Smith JC. Mechanism of Lignin Inhibition of Enzymatic Biomass Deconstruction. Biotechnol Biofuels. 2015;8:1-16.

9. Pescuma M, de Valdez GF, Mozzi F. Whey-derived valuable products obtained by microbial fermentation. Appl Microbiol Biotechnol. 2015;99:6183-96.

10. Guimarães PMR, Teixeira J, Domingues L. Fermentation of lactose to bioethanol by yeasts as part of integrated solutions for the valorisation of cheese whey. Biotechnol Adv. 2010;28:375-84.

11. Ling C. Whey to Ethanol: a Biofuel Role for Dairy Cooperatives? Res Rep. 2008;214:1-19.

12. Dragone G, Mussatto SI. Almeida e Silva JB, Teixeira J. Optimal fermentation conditions for maximizing the ethanol production by Kluyveromyces fragilis from cheese whey powder. Biomass Bioenergy. 2011;35:1977-82.

13. Silveira WB, Passos FJV, Mantovani HC, Passos FML. Ethanol production from cheese whey permeate by Kluyveromyces marxianus UFV-3: a flux analysis of oxido-reductive metabolism as a function of lactose concentration and oxygen levels. Enzyme Microb Technol. 2005;36:930-6.
14. Porro D, Martegani E, Ranzi BM, Alberghina L. Lactose/whey utilization and ethanol production by transformed Saccharomyces cerevisiae cells. Biotechnol Bioeng. 1992;39:799-805.

15. Kleerebezemab M, Hols P, Hugenholtz J. Lactic acid bacteria as a cell factory: rerouting of carbon metabolism in Lactococcus lactis by metabolic engineering. Enzyme Microb Technol. 2000;26:840-8.

16. Hugenholtz $\mathrm{J}$. The lactic acid bacterium as a cell factory for food ingredient production. Int Dairy J. 2008;18:466-75.

17. Solem C, Dehli T, Jensen PR. Rewiring Lactococcus lactis for ethanol production. Appl Environ Microbiol. 2013;79:2512-8.

18. Gasson MJ. Plasmid complements of Streptococcus lactis NCDO 712 and other lactic streptococci after protoplast-induced curing. J Bacteriol. 1983;154:1-9.

19. Wegmann U, Overweg K, Jeanson S, Gasson M, Shearman C. Molecular characterization and structural instability of the industrially important composite metabolic plasmid pLP712. Microbiol. 2012;158:2936-45.

20. Jensen P, Hammer K. Minimal requirements for exponential growth of Lactococcus lactis. Appl Environ Microbiol. 1993;59:4363-6.

21. Aleksandrzak-piekarczyk T, Kok J, Renault P, Bardowski J. Alternative Lactose Catabolic Pathway in Lactococcus lactis IL1403. Appl Environ Microbiol. 2005;71:6060-9.

22. Li Z, Ding S, Li Z, Tan T. L-lactic acid production by Lactobacillus casei fermentation with corn steep liquor-supplemented acid-hydrolysate of soybean meal. Biotechnol J. 2006;1:1453-8.

23. Aeschlimann A, von Stockar U. The effect of yeast extract supplementation on the production of lactic acid from whey permeate by Lactobacillus helueticus. Appl Microbiol Biotechnol. 1990;32:398-402.

24. Smid EJ, Konings WN. Relationship between utilization of proline and proline-containing peptides and growth of Lactococcus lactis. J Bacteriol. 1990;172:5286-92.

25. Ten Kortenaar PB, Hendrix BM, Van Nispen JW. Acid-catalyzed hydrolysis of peptide-amides in the solid state. Int J Pept Protein Res. 1990;36(March):231-5.

26. Kaiser K, Benner R. OCEANOGRAPHY : methods Hydrolysis-induced racemization of amino acids. 2005:318-325.

27. Hols P, Kleerebezem M, Schanck AN, Ferain T, Hugenholtz J, Delcour J, de Vos WM. Conversion of Lactococcus lactis from homolactic to homoalanine fermentation through metabolic engineering. Nat Biotechnol. 1999;17:588-92.

28. Becker J, Klopprogge C, Zelder O, Heinzle E, Wittmann C. Amplified expression of fructose 1,6-bisphosphatase in Corynebacterium glutamicum increases in vivo flux through the pentose phosphate pathway and lysine production on different carbon sources. Appl Environ Microbiol. 2005;71:8587-96

29. Wu H, Bennett GN, San KY. Metabolic control of respiratory levels in coenzyme Q biosynthesis-deficient Escherichia coli strains leading to fine-tune aerobic lactate fermentation. Biotechnol Bioeng. 2015;112:1720-6.

30. Janssens JH, Burris N. Woodward a., Bailey RB: lipid-enhanced ethanol production by Kluyveromyces fragilis. Appl Environ Microbiol. 1983;45:598-602.

31. Ghaly AE, El-Taweel AA. Effect of Nutrient Supplements Addition on Ethanol Production from Cheese Whey Using Candida pseudotropicalis Under Batch Condition. Appl Biochem Biotechnol. 1995;53:107-31.

32. Galbe M, Sassner P, Wingren A, Zacchi G. Process engineering economics of bioethanol production. Adv Biochem Eng Biotechnol. 2007; 108:303-27.

33. Zhang J, Chu D, Huang J, Yu Z, Dai G, Bao J. Simultaneous saccharification and ethanol fermentation at high corn stover solids loading in a helical stirring bioreactor. Biotechnol Bioeng. 2010;105:718-28.

34. Kasjet ER. Bioenergetics of lactic acid bacteria: citoplasmic pH and osmotolerance. FEMS Microbiol Rev. 1987;46:233-44.

35. Zafar S, Owais M, Saleemuddin M, Husain S. Batch kinetics and modelling of ethanolic fermentation of whey. Int J Food Sci Technol. 2005:40:597-604

36. Koebmann BJ, Solem C, Pedersen MB, Nilsson D, Jensen PR. Expression of Genes Encoding F1 -ATPase Results in Uncoupling of Glycolysis from Biomass Production in Lactococus lactis. Appl Environ Microbiol. 2002;68:4274-82.

37. Hädicke O, Bettenbrock K, Klamt S. Enforced ATP futile cycling increases specific productivity and yield of anaerobic lactate production in Escherichia coli. Biotechnol Bioeng. 2015;112:2195-9. 
38. Anderson D. Simple and Rapid Method for Isolating Large Plasmid Dna From Lactic Strepococci. Appl Environ Microbiol. 1983;46:549-52.

39. Sambrook J, Russell D. Molecular Cloning: A Laboratory Manual. New York: Cold Spring Harbor Laboratory Press; 2001.

40. Nørholm MHH. A mutant Pfu DNA polymerase designed for advanced uracil-excision DNA engineering. BMC Biotechnol. 2010;10:21.
41. Holo H, Nes I. High-frequency transformation, by electroporation, of Lactococcus lactis subsp. cremoris grown with glycine in osmotically stabilized media. Appl Environ Microbiol. 1989;55:3119-23.

42. Barkholt $\mathrm{V}$, Jensen AL. Amino acid analysis: determination of cysteine plus half-cystine in proteins after hydrochloric acid hydrolysis with a disulfide compound as additive. Anal Biochem. 1989;177:318-22.
Submit your next manuscript to BioMed Central and we will help you at every step:

- We accept pre-submission inquiries

- Our selector tool helps you to find the most relevant journal

- We provide round the clock customer support

- Convenient online submission

- Thorough peer review

- Inclusion in PubMed and all major indexing services

- Maximum visibility for your research

Submit your manuscript at www.biomedcentral.com/submit
() BioMed Central 